\title{
A Study of Different Building Energy Lighting Simulation Tools in Practice
}

\author{
Syed Rizwan Ali ${ }^{1, *}$, Laime Mahjdoubi ${ }^{2}$, Azmat Khan ${ }^{1}$ \\ ${ }^{1}$ Department of the Computer Science, Bahria University Karachi Campus (BUKC), Pakistan \\ ${ }^{2}$ Department of the Build Environment, University of the West of England, United Kingdom
}

Copyright $(\mathcal{C} 2015$ by authors, all rights reserved. Authors agree that this article remains permanently open access under the terms of the Creative Commons Attribution License 4.0 International License

\begin{abstract}
For the past 50 years, wide varieties of lighting simulation software or tools have been developed to enhance use throughout the building energy lighting community to achieve the efficiency goals through daylighting. Architects and building designers require effective simulation design tools for analysis and understanding the complex behavior of building design. The government officials and the experienced lighting modelers are even also confused sometimes by a wide range of day lighting simulation software and feel uncertain about the validity and accuracy of the light energy calculation. These lighting simulation software or tools are used by the 3D architectural simulation tools. This research has been conducted into UWE Bristol, UK to reveal ECOTECT is more reliable and accurate daylighting simulation software and presenting study was a sub part. Its main aim is to discuss the important use of lighting simulation software for efficiency in building design. And to compare the most widely use lighting simulation tools that are claiming to predict accuracy for enhancing the daylighting performance in building design.
\end{abstract}

Keywords Uncertainty, Accuracy, Lighting Simulation

\section{Introduction}

A simulation is an imitation of some real thing, state of affairs, or process. The art of simulating something generally entails representing certain key characteristics or behaviors of a selected physical or abstract system.

Daylighting is an essential element of any building. Proper lighting improves the aesthetics of indoor spaces and provides illumination for tasks and activities. An efficient daylighting strategy, including natural daylighting, can provide proper levels of illumination and reduce energy costs. Maximum benefits from daylighting are best obtained by integration of natural and artificial lighting sources early in the building design process.

According to [9] lighting simulation software is an attempt to provide an accurate simulation in building design, thus it is perceptually, mathematically and logically correct and [9] also recommended that a great number of lighting simulation software and tools have been developed in the last 10 years, due to the availability of the many lighting simulation software in the built environment industry that makes ambiguity for the designers to select the right lighting simulation software.

However, use and availability of such sophisticated lighting simulation software or tools in building design practices is currently limited. Alternatively quantitatively derived lighting simulation software could serve to predict energy savings thus help architects or designers in making informed building design decisions [2].

\section{Role of Natural Lighting}

Natural lighting, or daylighting, refers to the lighting of an area by allowing in diffuse natural light. Because the sun's position in the sky varies throughout the day, is often obscured by clouds, and experiences significant changes in intensity throughout the year, it does not make a suitably reliable light source with which to light the interior of buildings. As a result, direct light from the sun is known as sunlight is rarely included in architectural daylighting calculations.

The primary aim of daylighting is to provide sufficient light for tasks performed within a space by providing enough apertures that let in diffuse light from the sky, but keep out direct light from the sun. On a clear day for example, outside light levels may be in the order of 55 to 60, 000 Lux whilst on an overcast day in winter this might fall to around 8 to 10,000 Lux. The required light level inside a building ranges from 100 Lux in a corridor, to 300 Lux in the average office and 1,000 Lux in a well-lit supermarket. Thus, with some thoughtful design, daylighting can potentially provide more than sufficient light for most buildings [9].

Light and heat normally come together. However, for the same lighting intensity, the amount of heat produced by 
different lights can vary significantly. It turns out that in terms of the number of lighting lumens per watt of heat energy, daylight is about five times more efficient than a normal incandescent globe and as much as twice as efficient as a fluorescent tube.

In a typical office building, turning the lights off and substituting daylight alone can reduce overall heat loads by as much as $40 \%$, principally by reducing over illumination near perimeter windows [9].

Lighting technologies are as follows:

- Lamps: Lighting sources, like fluorescent and incandescent light bulbs, and solid state lighting. Commonly called light bulbs, produce light.

- Ballasts: It is used with electric discharge lamps such as fluorescent lamps. Ballasts transform and control electrical power to the light.

- Luminaries: Complete lighting units that contain the bulbs and ballasts (if necessary), are known as Luminaries.

- Lighting Controls: Devices such as timers and sensors that can save energy by turning lights off when not needed.

- Daylighting: The use of natural light in a building design is termed as Daylighting.

\subsection{Luminance and Illuminance}

Luminance: the number of candelas per unit surface area of an extended source. Here, 'surface area' indicates the projected area of the true surface, towards the viewing direction.

Illuminance: The luminous intensity that is incident on per unit area of a surface is Illuminance. One Lux equals one lumen per square meter. One lumen per square foot is equal to one foot-candle [12].

Lux: an illuminance equivalent to one lumen per square meter is termed as Lux.

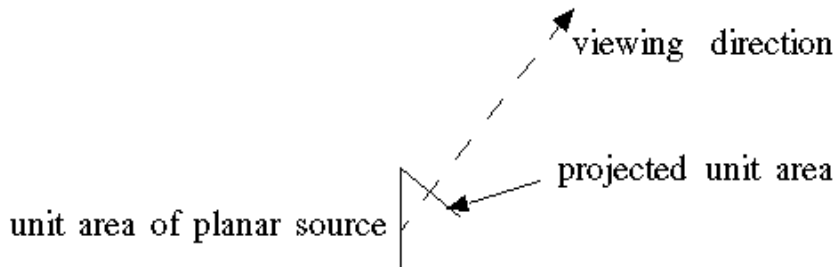

Figure 1. Luminance [13]

\subsubsection{Sky Illuminance:}

It is the total illuminance from the entire sky dome falling on an unobstructed horizontal plane.

\subsubsection{Luminous Efficacy:}

Luminous Efficacy is the ratio between the amounts of light that a source generates relative to its heat output. It is measured in lumens per watt $(1 \mathrm{~m} / \mathrm{W})$. A $150 \mathrm{~W}$ incandescent bulb has a luminous efficacy of between $16-40 \mathrm{~lm} / \mathrm{W}$; while diffuse skylight is around $150 \mathrm{~lm} / \mathrm{W}$ (i.e. produces more than three times the light for each watt of heat generated [3].

The main aim of this research is to compare the accuracy and reliability of different daylighting simulation software's in building design. Particularly it will investigate the claim made by three different lighting software.

\subsubsection{Objectives:}

- To evaluate the performance of three different lighting software; ECOTECT, Energy Plus, \& Radiance.

- To validate the software using experimental design

- To ascertain the approximation of the following lighting methods real life measurement.

- To propose the future trends in lighting simulation software for building design and construction.

\section{British Research Establishment (BRE) Standers}

British Research Establishment (BRE) is an organization that carries out the research, consultancy and testing for the construction and build environment sectors in the United Kingdom. Among the BRE's areas of interest are participation in the preparation of national and international standards and building codes, including the U.K building regulations [9].

The organization is now funded by income from its commercial programmers, the BRE bookshop, contracted work, and by bidding for research funding from government and the industries it serves. It is also a UKAS Accredited Testing Laboratory.

\subsection{BRE Programs}

Validity reflects that how accurately the research findings represent the real world situation [5]. And [1] Suggested '...validity refers to the general correctness of the fact or evidence used in understanding and studying behavior ...'

Because of the nature of research problem, it would be difficult to clearly specify the validity of the research. But based on the fact that the research will be done by analyzing and observing the existing software, it could be argued that the proposed research will produce valid results.

\subsection{BRE Research}

Since privatization there have been claims that the Blue Sky research for which the BRE was well known has been compromised by commercial pressures.

In 2005 the Select Committee on Environmental Audit expressed their concern that there was a lack of significant funding for research and development of sustainable construction methods in the UK, with funding for the BRE having been drastically cut in the previous 4 years. As a result, many of the sustainable building materials used in the 
UK are imported from Germany, Switzerland and Austria, countries which have taken the lead in research in this area [9].

\section{Different Lighting Simulation Tools}

For the past 50 years, wide varieties of lighting simulation software or tools have been developed to enhance use throughout the building energy lighting community to achieve the efficiency goals through daylighting. Architects and building designers require effective simulation design tools for analysis and understanding the complex behavior of building design [4].

Suggests [9] the government officials and the experienced lighting modelers are even also confused sometimes by a wide range of day lighting simulation software and feel uncertain about the validity and accuracy of the light energy calculation. These lighting simulation software or tools are used by the $3 \mathrm{D}$ architectural simulation tools. In addition, the key issues are:

- Avoid in terms of cost, time, and effort

- Get more accurate results of building design lighting performance

- Sustainability issues

- Save energy

- Use more daylighting and reduce the use of artificial lighting

\subsection{Comparison between the Major Simulation Tools in Practice}

At present, researchers have developed a wide range of day lighting simulation software's that are available in the industry. Despite the fact of availability of many lighting simulation software's, ambiguity for the designers and architects to select the appropriate software is still a concern.

Several lighting simulation software's are evaluated below:

\section{- ECOTECT, \\ - Energy Plus, \\ - \& Radiance}

\subsubsection{ECOTECT}

ECOTECT is a highly visual architectural design and analysis software that is capable of linking a comprehensive $3 \mathrm{D}$ modeler with a broad range of performance analysis functions. In addition to table based reports and standard graph, analysis results can be mapped over building surfaces or displayed directly within the spaces. Visualization of volumetric and spatial analysis results, including 3D CFD data is also included [6]. Interactive acoustic and solar ray tracing are provided along with Real time animation features that updates in real time with changes to material property and building geometry.

Validation and Accuracy: Great time and effort has been spent with this build of ECOTECT on validating all the thermal, lighting, solar and acoustic calculation processes used in ECOTECT. Advice and feedback on real projects from engineers, researchers and postgraduate students, direct comparisons with other analysis software's and validation against software accuracy standards and technical memorandums have improved the early ECOTECT a lot [8].

Expertise Required: Working knowledge of $\mathrm{CAD}$ and environmental design experience are useful but not necessary to progress in ECOTECT. The software is good at teaching the novice environmental designer a lot of vital concepts necessary for effective building design. Extensive help and tutorials are provided along with the software [11].

Users: More than 2000 individual licenses worldwide, taught at approximately 60 universities mainly in Australia, UK and US.

Audience: Building designers, engineers, Architects, environmental consultants, corporate builders and enthusiasts.

Input: Instinctive 3D CAD GUI allows validation of the simplest design sketch to highly complex 3D models which allows the user to import 3DS and DXF files.

Outputs: ECOTECT own analysis function use of a broad range of information graphics methods which can be saved as Bitmaps or animations. Table data can also be output with great ease. For more specific analysis or validation you can also export to different file formats such as; RADIANCE, POV Ray, VRML, AutoCAD DXF, EnergyPlus, AIOLOS, HTB2, CheNATH, ESP-r, ASCII Mod files, and XML

Computer Platform: Windows 9X NT, 2000 \& XP (Mac OS support also provided).

\subsubsection{Energy Plus}

Created by CSIRO, Energy Plus is a splendid design analysis tool, for approximating energy consumption and cost at the beginning of design stage. The gui allows swift and precise model creation and manipulation. Energy Express provides a dynamic multi-zone heat dissipation model linked to an integrated HVAC model so that zone temperatures are impacted by any HVAC shortcomings. Energy Express for Architects provides graphic input and editing geometry, viewing multiple reports, comparison of different designs and results, basic HVAC examples, and comprehensive online support [10]. Energy Plus for Engineers provides those capabilities along with peak load estimating and detailed HVAC model, graphic editing of air handling system and thermal plant layouts.

Expertise Required: Basic Working knowledge of HVAC and environmental design experience can be useful.

Users: Approximately 250 licenses, of which mainly in Australia.

Audience: Engineers, Architects, researchers and enthusiasts.

Computer Platform: Windows 9X NT, 2000 \& XP.

\subsubsection{RADIANCE}

RADIANCE is an advanced lighting simulation and rendering environment. It calculates spectral irradiance 
(illuminance \& color) and spectral radiance values (illuminance \& color) for exterior and interior spaces considering inter-reflection electric lighting and daylight. It is commonly used by architects and designers to predict illumination, visual quality and visual aspect of design spaces. It is also used by researchers to analyze new lighting and daylighting technologies and study visual comfort and similar quantities related to the visual environment [10].

Expertise Required: High level of computer literacy required; 4 days learning curve, minimum.

Users: More than 200 users worldwide.

Audience: Lighting, daylighting, and architectural designers.

Input: Materials and geometry of design space, including surface reflectance characteristics and luminaries photometry. Translators are also available for DXF, Architrion, and IESNA standard luminaries' files. ArchiCAD and others are additional translators that have been written by third parties. Vision3D can prepare Radiance input directly. It is also a third-party (shareware) CAD program.

Output: Visual comfort levels, plots and contours, Luminance and illuminance values, photograph-quality images and movie animations.

Computer Platform: UNIX-compatible workstation, e.g. Sun, Silicon Graphics, Hewlett Packard, DEC station, NeXT, Mac II running A/UX; 8- or 25-bit color display, $20 \mathrm{MB}$ of hard disk space, $8 \mathrm{MB}$ of RAM, and math coprocessor recommended.

Programming Language: C (K \& R standard)

Strengths: Physical accuracy in a graphics rendering package, reliability and source code availability; arbitrary surface geometry and reflectance properties.

Weaknesses: Lacks a proper GUI, complete documentation, and examples. Few CAD formats supported.

\section{Advantages \& Limitations}

As different programs can perform various types of studies, analysis and evaluations, the user needs to be aware of the several modeling and data requirements before starting and modeling/importing geometry into particular software. For example; for thermal analysis, climate data study and CAD geometry in a suitable manner is important; and appropriate, comprehensive material data is required for almost all other types of analysis.

Proposed study found that many users are relying on a single simulation tool when they might be more productive having a suite of tools from which to choose. Early design decisions may not require a detailed simulation program to deal with massing or other early design problems. Recommendation is that users to consider adopting a suite of tools which would support the range of simulation needs they usually see in their practice.

\section{Conclusions}

As the research depicted that there is a number of lighting simulation tools available in the industry and a large amount of work is needed to identify performance, accuracy and meaningful results. But however, it is still hard to choose the appropriate software.

The study found that even among the 'mature' tools, there was not quite a common language to describe what the tools could do. There was much ambiguity which will continue to require additional work to resolve in the future. Research also found that there was a relatively new level of attention and interest in publishing validation results. Several program developers also indicated that they plan to make the simulation inputs available to users for download in the near future. Furthermore, the trustworthiness of this software's is also a concern. Do the tools really perform the capabilities indicated, and which level of effort by the user is involved? How detailed is the model behind a tick in the table? For open source tools, everyone can check the model and adapt it. For the other tools, only very detailed BESTEST like procedures can give the answer. We may need a way for users to provide feedback and ratings for these in the future.

Now the question arises, what is the next generation of the report? Dynamic web based community resource with direct links for each tool to example input files for each capability as well as the suite of validation inputs. And to some extent it has also started implementing as different programs can perform various types of studies.

ECOTECT were selected for this research study since it can be used to predict the internal illuminance with a high degree of accuracy under overcast sky conditions.

\section{Acknowledgements}

I am very grateful to Dr. Prof Lamine Mahdjoubi from UWE, UK for his appropriate and constructive suggestions to improve this research and also Dr. Humera Farooq HoD CS Dept. BUKC for her support.

\section{REFERENCES}

[1] Adams, G.R. \& Schvaneveldt, J.D, (1985) Understanding Research Methods. Longman Inc, New York, USA.

[2] Ahmed, A.Z. \& Ibrahim, N., (2006). ISESCO Science and Technology Vision. A Simple Prediction Tool for Energy Savings due to Daylighting in Malaysia. 2. Pp 25-29.

[3] Autodesk (2015). ECOTECT definition glossary, "Def of Luminous Efficacy". [Online] Available from: wiki.naturalfrequency.com/glossary/12 [Accessed 02 August 2015].

[4] IBPSA Conference, (2015) "Contrasting the Capabilities of the Building Energy Performance Simulation Programs" [online].Availablefrom:http://www.researchgate.net/publicat ion/222537377_Contrasting_the_Capabilities_of_Building 
Energy_Performance_Simulation_Programs [Accessed 13 March 2015].

[5] Collis, J. \& Hussey, R, (2003) Business Research: A practical guide for undergraduate and postgraduate students, 2nd Ed. Palgrave MacMillan, London, UK.

[6] Engr. Syed Rizwan Ali, Lamine Mahdjoubi., \& Azmat Khan. JMEST, "The Comparison Study between UK Daylighting Simulation - Malaysia Daylighting Simulations Due To Overcast Sky Conditions", Available from: http://www.jmest.org/wp-content/uploads/JMESTN4235086 2.pdf [Accessed by 15 July 2015].

[7] Edward Yan-Yung Ng, Lam Khee Poh, Wu Wei, Takehiko Nagakura, (2001). Elsevier Science, "Automation in Construction. Advanced lighting simulation in architectural design". pp 365-379.

[8] Square one, (2015). "ECOTECT Guide. "Daylighting” [Online]From:http://www.toolsforsustainability.com/index.p hp/component/content/article/9-reviews/software/129-square -one-ecotect-v5556-superceded-by-autodesk-ecotect [Accessed 03 June 2015].

[9] Sam. C. M. Hui., (2000). "Building energy efficiency standards in Hong Kong and mainland China", In: ACEEE Summer Study on Energy Efficiency in Buildings, 20-25
August 2000, Pacific Grove, California.

[10] National Master, (2005). "Encyclopedia Building Research Establishment". International standards and building codes. [Online] Accessed from: http://www.nationmaster.com/encyclopedia/Building-Resear ch-Establishment [12 November 2008].

[11] U.S. department of energy (2008). "US lighting cost and efficient building percentage reduction" [online]. EERE (Energy Efficiency and Renewable Energy). Available from: http://wwwl.eere.energy.gov/buildings/lighting.html [Accessed: 25 November, 2008].

[12] International Commission (1989)." The Measurement of Luminous Flux" [online]. CIE Lighting Quality \& Energy EfficiencyConference.Availablefrom:http://www.cie.co.at/in dex.php/Publications/index.php?i_ca id=359 [Accessed: 25 July, 2015].

[13] Schwartz's, H. (1996). Visual Perception. "A Clinical Orientation". Appleton \& Lange [online] from: http://scubageek.com/articles/wwwlux.html [Accessed: 03 August, 2015]. 